\title{
Selectivity of odorant receptors in insects
}

\author{
Jonathan D. Bohbot and Joseph C. Dickens* \\ Invasive Insect Biocontrol and Behavior Laboratory, Plant Sciences Institute, Henry A. Wallace Beltsville Agricultural Research Center, \\ Agricultural Research Service, United States Department of Agriculture, Beltsville, MD, USA
}

\section{Edited by:}

Dieter Wicher, Max Planck Institute for Chemical Ecology, Germany

Reviewed by:

Klemens F. Störtkuhl, Ruhr-Universität Bochum, Germany

Guenter Gisselmann, Ruhr-Universität

Bochum, Germany

${ }^{*}$ Correspondence:

Joseph C. Dickens, Invasive Insect Biocontrol and Behavior Laboratory, Plant Sciences Institute, Henry A.

Wallace Beltsville Agricultural

Research Center, Agricultural

Research Service, United States

Department of Agriculture, Building

007, Room 030, 10300 Baltimore

Avenue, Beltsville, MD 20705, USA.

e-mail: joseph.dickens@ars.usda.gov
Insect olfactory receptors (ORs) detect chemicals, shape neuronal physiology, and regulate behavior. Although ORs have been categorized as "generalists" and "specialists" based on their ligand spectrum, both electrophysiological studies and recent pharmacological investigations show that ORs specifically recognize non-pheromonal compounds, and that our understanding of odorant-selectivity mirrors our knowledge of insect chemical ecology. As we are progressively becoming aware that ORs are activated through a variety of mechanisms, the molecular basis of odorant-selectivity and the corollary notion of broad-tuning need to be re-examined from a pharmacological and evolutionary perspective.

\section{Keywords: olfaction, specialist, generalist, olfactory receptor, semiochemical}

\section{INTRODUCTION}

Insect olfactory receptor $(\mathrm{OR})$ genes belong to a distinct gene family encoding heteromeric (Neuhaus et al., 2005; Lundin et al., 2007; Smart et al., 2008) ligand-gated ion channels comprised of a variable sensing component and an obligatory co-receptor, named Orco (Nakagawa et al., 2005; Sato et al., 2008; Wicher et al., 2008). Like hormone receptors and neuroreceptors, ORs recognize biologically meaningful chemical ligands, and shape responses of olfactory sensory neurons (OSNs), thus regulating many behaviors. Reading errors on the part of ORs may have deleterious consequences for species propagation; therefore, we should expect odorant-selectivity to be a key feature of olfactory systems.

Early electrophysiological studies proposed that OSNs could be classified as "specialists" which responded to pheromone components or "generalists" which responded to host or plant odors (Boeckh etal., 1965). Large-scale functional studies of ORs in Drosophila melanogaster (Hallem et al., 2004) and Anopheles gambiae (Carey et al., 2010; Wang etal., 2010a) suggest a similar classification for the majority of ORs as generalist-type sensors detecting food odors, and a smaller OR contingency of pheromone sensors (Hallem and Carlson, 2006; Figure 1A). However, recent electrophysiological studies and pharmacological investigations suggest that "generalist" receptors may in fact specifically recognize non-pheromonal compounds (Carey et al., 2010; Wang et al., 2010a), insect repellents (Pellegrino et al., 2011) and other synthetic compounds (Jones et al., 2011, 2012). Moreover, functional screens (Carey et al., 2010; Wang et al., 2010a) using high concentrations of natural odorants and synthetic compounds, which elicit agonist (Xia et al., 2008; Bohbot and Dickens, 2010), antagonist (Bohbot and Dickens, 2010), and synergistic effects
(Bohbot and Dickens, 2012) on OR activity, suggest complex OR-ligand and OR-OR interactions. Finally, the functional distinction between "generalists" and "specialists" raises the fundamental question regarding the selective advantage and cost associated with maintaining a large pool of promiscuous receptors unable to distinguish structurally variable odorants. The developing field of OR pharmacology challenges this proposition by unraveling the complex factors contributing to the mechanism of OR activation.

\section{NON-PHEROMONE SELECTIVITY}

Electrophysiological studies and pharmacological investigations suggest that "generalist" receptors may specifically recognize nonpheromonal compounds (Dickens, 1990; Syed and Leal, 2007; Bohbot and Dickens, 2009; Bohbot et al., 2010; Hughes etal., 2010). For example, OR8-Orco is expressed in one of three OSNs in the basiconic sensilla on the maxillary palp of mosquitoes (Lu etal., 2007). A functional study in a heterologous system revealed that OR8-Orco specifically recognizes one enantiomer of the host attractant, 1-octen-3-ol, and responds with much lower sensitivity to structurally similar compounds (Bohbot and Dickens, 2009). Millimolar concentrations of compounds with little or no resemblance to indoles (e.g., benzaldehyde) elicit significant responses from OR2-Orco and OR10-Orco (Bohbot et al., 2007) suggesting a group of broadly tuned receptors (Bohbot et al., 2010). However, including indole and its methylated analog skatole (Hughes et al., 2010) narrows the tuning profile of both receptors. A. gambiae OR35-Orco and OR65-Orco are specifically tuned to plant-derived compounds at low concentrations (Wang et al., 2010a), providing a molecular basis for the specificity of "generalist" OSNs (Bruce and Pickett, 2011). The sensitivity and 


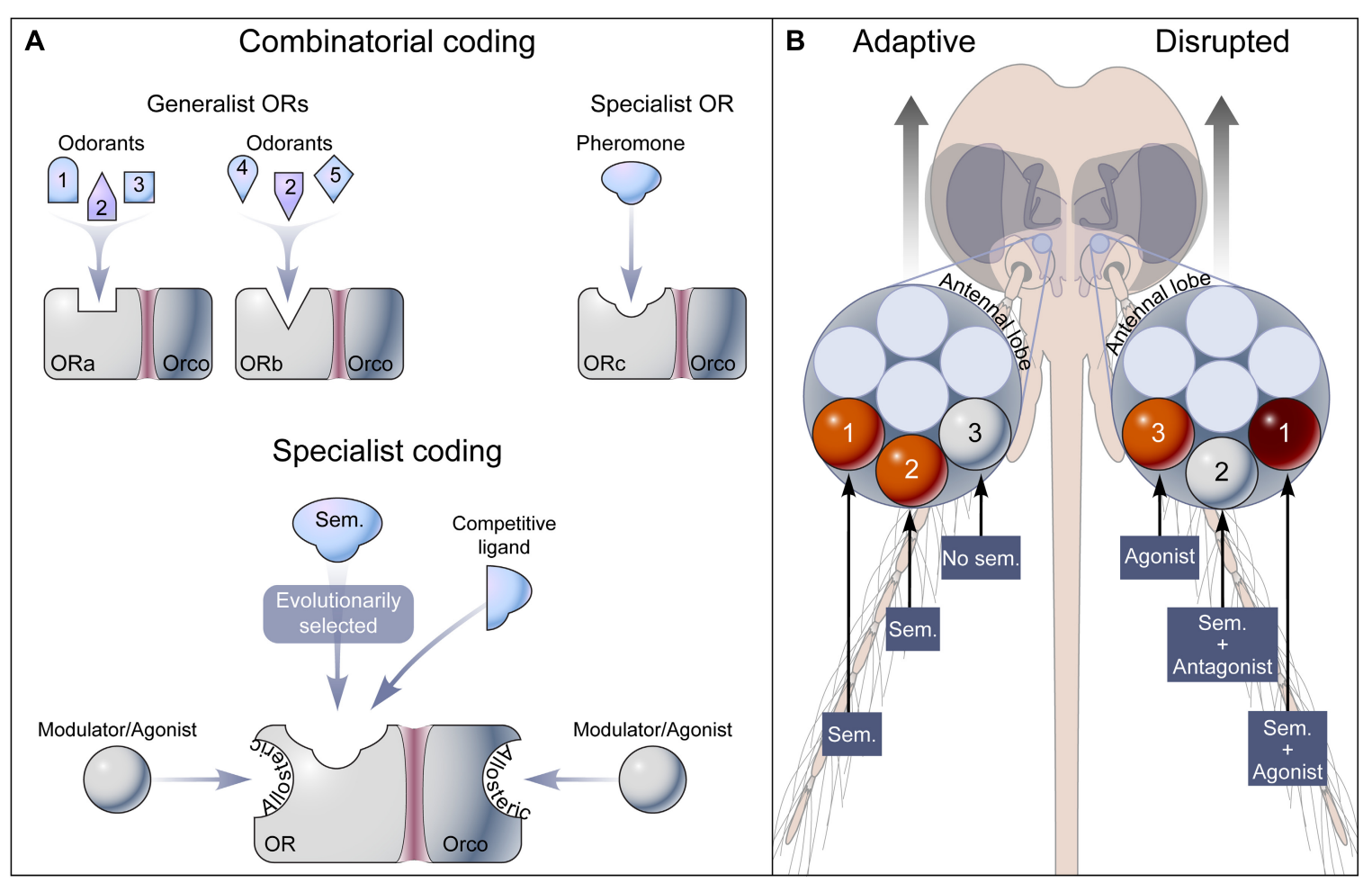

FIGURE 1 | Olfactory coding and disruption of insect behavior through OR modulation. (A) Two models of receptor codes for odorants. In the concept of combinatorial coding, a general odorant (e.g., Odorant 2) is detected by a unique set of generalist ORs (ORa-Orco and ORb-Orco), while a pheromone is specifically recognized by a specialist OR (ORc-Orco). Broad-tuning results from promiscuous orthosteric sites on ORs. The specialist coding model assumes that adaptive evolution shapes orthosteric sites to specifically recognize low concentrations of semiochemicals (Sem.), and that apparent broad-tuning is caused by high concentrations of chemicals interacting with orthosteric and allosteric sites on the receptor. (B) Semiochemicals (Sem.) alone or in combination activate labeled-line pathways from OR to glomerulus (orange) in the antennal lobe leading to adaptive physiological or behavioral outputs. Modulation of OR activity, including agonism (orange), antagonism (white), and synergism (red), results in abnormal glomerulus activation leading to disrupted physiological and behavioral responses. specificity exhibited by these non-pheromonal receptors is consistent with those of pheromone receptors assessed using similar methodologies (Wang et al., 2010b; Wanner et al., 2007, 2010).

\section{SELECTIVITY OF INSECT REPELLENTS}

How can we explain the activation (i.e., change in membrane potential) of ORs by chemicals with little or no resemblance to semiochemical ligands? Insect repellents (Dethier et al., 1960) can specifically activate ORs (Xia et al., 2008; Bohbot and Dickens, 2010; Bohbot et al., 2011), elicit responses from OSNs (Ditzen et al., 2008; Syed and Leal, 2008; Pellegrino et al., 2011) and disrupt behavior (Debboun et al., 2007; Ditzen et al., 2008). While it is unclear whether the agonist effect of an insect repellent (Xia et al., 2008; Bohbot and Dickens, 2010; Bohbot et al., 2011) results from interactions with the same odorant-recognition site on ORs, their chemical structures provide clues regarding operative mechanisms. For example, based on its structural similarity with octenol, 2-undecanone may interact with the orthosteric site on the octenol receptor (Bohbot and Dickens, 2010), an analysis consistent with OR8-Orco structure-function studies (Bohbot and Dickens, 2009; Grant and Dickens, 2011) showing a correlation between the chemical structure of octenol analogs (e.g., octenone) and their agonist effect on the octenol receptor. Alternatively, other insect repellents sharing little structural similarity with octenol may act as allosteric agonists (Figure 1A; Bohbot et al., 2011), as was clearly shown with Orco agonists (Jones et al., 2011; Bohbot and Dickens, 2012).

\section{CONCENTRATION-DEPENDENT SPECIFICITY}

Using a panel of 110 odorants, Hallem and Carlson (2006) noted that broadly tuned ORs were narrowly tuned when potential ligands were delivered at low concentrations, a situation encountered by insects in nature. This observation does not exclude the possibility that ligand-selectivity may depend on odorant concentration (de Bruyne and Baker, 2008) as well as on the collective activity of different ligand-binding sites on a receptor. Indeed, analogs of ligands may interact with the same site whereas structurally unrelated compounds may be recognized by topographically distinct sites on the receptor (Figure 1A). This allosteric agonism may have been attributed to interactions with a promiscuous orthosteric site. In functional screens (Hallem et al., 2004; Hallem and Carlson, 2006; Carey et al., 2010; Wang et al., 2010a), high concentrations (micromolar and above) and doses ( $10^{-2}$ dilutions) of natural odorants and synthetic compounds elicit OR agonist (Xia et al., 2008), antagonist (Bohbot and Dickens, 2010; Bohbot et al., 2011), and synergistic (Bohbot and Dickens, 2012) effects, further suggesting 
that the breadth of tuning of ORs is amplified by chemical activators of various chemical structures and properties. High doses of benzaldehyde - a common plant compound - activate and inhibit $42 \%$ of A. gambiae ORs when expressed in the Drosophila empty neuron system (Carey et al., 2010), an effect that disappears at lower concentrations (Hallem and Carlson, 2006). At high concentration, benzaldehyde may act as an orthosteric competitor, or as an allosteric agonist, but at low concentration it may be recognized by a specific OR. Indole reception in mosquitoes further illustrates this problem. While micromolar concentrations of compounds with little or no resemblance to indoles (e.g., benzaldehyde) elicit strong responses from OR2 and OR10 (Bohbot et al., 2010), the receptors exhibit nanomolar sensitivity to indole (Bohbot et al., 2010) and skatole (Pelletier et al., 2010), respectively. Insect repellents exert their agonist effect at millimolar concentrations (Bohbot and Dickens, 2010), which is at least 1000fold higher than pheromones (Wang et al., 2010b; Wanner et al., 2007, 2010) and other non-pheromonal attractants (Bohbot and Dickens, 2009; Bohbot et al., 2010; Hughes et al., 2010).

\section{ADAPTIVE SELECTIVITY OF ODORANT RECEPTORS}

The mosquito attractants, octenol, indole, and skatole are known chemical signals whose interactions with OR8, OR2, and OR10, respectively, are likely adaptive when encountered at low concentrations. Some insect repellents, such as DEET and IR3535 do not occur in nature, while others are naturally occurring compounds, e.g., 2-undecanone (Farrar and Kennedy, 1987) or p-menthane-3,8-diol (PMD), but are not known to be experienced by mosquitoes (Debboun et al., 2007). Insect repellents do not elicit evolutionary adaptive behaviors in mosquitoes, but rather disrupt the final stages of host attraction (Figure 1B). It is therefore important to clarify evolutionary assumptions and the definitions involved in describing the complex relationships observed between ORs and ligands with variable chemical structures, properties, and origins. There is no fundamental reason to consider the structural and chemical bases underpinning odorantselectivity to differ from other ligand-gated receptor types. The selective pressure driving ligand-selectivity may be greater for ORs since they might be exposed to a greater number of pharmacologically active compounds than other conventional ligand-gated ion channels and G-protein coupled receptors.

According to Neubig et al. (2003), "The regions of the receptor macromolecule to which ligands bind are referred to collectively as the recognition site(s) of the receptor. Those at which the endogenous agonist binds are termed primary or orthosteric sites whereas other ligands may act through allosteric sites." Considering the pharmacological and evolutionary arguments cited above, the definition of a semiochemical (Law and Regnier, 1971), which is equivalent to an endogenous agonist, may be expanded to include the following criteria:

\section{REFERENCES}

Boeckh, J., Kaissling, K. E., and Schneider, D. (1965). Insect olfactory receptors. Cold Spring Harb. Symp. Quant. Biol. 30, 263-280.

Bohbot, J., Pitts, R. J., Kwon, H. W., Rutzler, M., Robertson, H. M.,

1. Semiochemicals are natural chemicals of organic and inorganic origin.

2. Semiochemicals elicit evolutionary adaptive physiological and behavioral responses (Figure 1B).

3. Semiochemicals selectively and reversibly bind to evolutionarily selected orthosteric site(s) on ORs (Figure 1A).

4. Semiochemicals activate ORs at low concentrations.

\section{CONCLUSION}

The apparent tuning breadth of insect ORs may reflect methodological contingencies (Bruce and Pickett, 2011) and the collective activity of multiple ligand-binding sites. Care should be taken when inferring evolutionary mechanisms from pharmacological relationships using high odorant concentrations and incomplete knowledge of insect chemical ecology. Odorants and other compounds have multiple effects on OR activity and may be classified as semiochemicals, orthosteric agonists, allosteric modulators, or allosteric agonists.

The ideas presented here challenge the current paradigm of the molecular basis of odor coding, which proposes that general odorants activate ORs in a combinatorial fashion (Malnic et al., 1999) and that only pheromones activate narrowly tuned receptors (Hallem et al., 2004; Hallem and Carlson, 2006). Perhaps the biggest challenge to the study of odorant-selectivity (i.e., the degree of promiscuity of OR orthosteric sites) is matching ORs to their cognate semiochemicals (Bruce and Pickett, 2011). While the number of naturally occurring odorants is unknown, it is likely that only a small fraction of these odorants has been identified. As knowledge of insect chemical ecology increases and the library of odorants expands, so will the odor space of insect ORs narrow (Hallem and Carlson, 2006). In the meantime, the current understanding of OR-semiochemical pairs may be further explored at the pharmacological, physiological, and behavioral levels, and ultimately X-ray crystallography studies and mutagenesis experiments (Pellegrino et al., 2011) will identify ligand recognition sites and functionally characterize them. These advances and modern high throughput screening approaches will guide efforts aimed at the discovery and development of the next generation of chemicals aimed at altering OR activity and disrupting olfactory-driven behaviors of arthropod disease vectors and agronomic pests (Figure 1B).

\section{ACKNOWLEDGMENTS}

The authors are grateful to Drs R. Jason Pitts (Vanderbilt University) and Richard G. Vogt (University of South Carolina) for their critical reading and useful comments of early versions of the manuscript. This work was supported in part by a grant to Joseph C. Dickens from the Deployed War Fighter Protection (DWFP) Research Program, funded by the U.S. Department of Defense through the Armed Forces Pest Management Board (AFPMB).

in the yellow fever mosquito Aedes aegypti. PLoS ONE 4, e7032. doi: 10.1371/journal.pone.0007032

Bohbot, J. D., and Dickens, J. C. (2010). Insect repellents: modulators of mosquito odorant receptor activity. PLOS ONE 5, e12138. doi: 10.1371/journal.pone. 0012138 characterization of the Aedes aegypti odorant receptor gene family. Insect Mol. Biol. 16, 525-537.

Bohbot, J. D., and Dickens, J. C. (2009). Characterization of an enantioselective odorant receptor
Bohbot, J. D., and Dickens, J. C. (2012). Odorant receptor modulation: ternary paradigm for mode of action of insect repellents. Neuropharmacology 62, 2086-2095. 
Bohbot, J. D., Fu, L., Le, T. C., Chauhan, K. R., Cantrell, C. L., and Dickens, J. C. (2011). Multiple activities of insect repellents on odorant receptors in mosquitoes. Med. Vet. Entomol. 25, 436-444.

Bohbot, J. D., Jones, P. L., Wang, G., Pitts, R. J., Pask, G. M., and Zwiebel, L. J. (2010). Conservation of indole responsive odorant receptors in mosquitoes reveals an ancient olfactory trait. Chem. Senses 36, 149-160.

Bruce, T. J., and Pickett, J. A. (2011). Perception of plant volatile blends by herbivorous insects - finding the right mix. Phytochemistry 72, 1605-1611.

Carey, A. F., Wang, G., Su, C., Zwiebel, L. J., and Carlson, J. R. (2010). Odorant reception in the malaria mosquito Anopheles gambiae. Nature 464, 66-71.

Debboun, M., Frances, S. P., and Strickman, D. (2007). Insect Repellents: Principles, Methods, and Uses. Boca Raton, FL: CRC Press.

de Bruyne, M., and Baker, T. C. (2008). Odor detection in insects: volatile codes. J. Chem. Ecol. 34, 882-897.

Dethier, V. G., Barton Browne, L., and Smith, C. N. (1960). The designation of chemicals in terms of the responses they elicit from insects. $J$. Econ. Entomol. 53, 134-136.

Dickens, J. C. (1990). Specialized receptor neurons for pheromones and host plant odors in the boll weevil, Anthonomus grandis Boh. (Coleoptera: Curculionidae). Chem. Senses 15, 311-333.

Ditzen, M., Pellegrino, M., and Vosshall, L. B. (2008). Insect odorant receptors are molecular targets of the insect repellent DEET. Science 319, 1838-1842.

Farrar, R. R., and Kennedy, G. G. (1987). 2-Undecanone, a constituent of the glandular trichomes of Lycopersicon hirsutum f. glabratum: effects on Heliothis zea and Manduca sexta growth and survival. Entomol. Exp. Appl. 43, 17-23.

Grant, A. J., and Dickens, J. C. (2011). Functional characterization of the octenol receptor neuron on the maxillary palps of the yellow fever mosquito, Aedes aegypti. PLoS ONE 6, e21785. doi: 10.1371/journal.pone.0021785

Hallem, E., Ho, M. G., and Carlson, J. R. (2004). The molecular basis of odor coding in the Drosophila antenna. Cell 117, 965-979.

Hallem, E. A., and Carlson, J. R. (2006) Coding of odors by a receptor repertoire. Cell 125, 143-160.

Hughes, D. T., Pelletier, J., Luetje, C. W., and Leal, W. S. (2010). Odorant receptor from the southern house mosquito narrowly tuned to the oviposition attractant skatole. J. Chem. Ecol. 36, 797-800.

Jones, P. L., Pask, G. M., Rinker, D. C., and Zwiebel, L. J. (2011). Functional agonism of insect odorant receptor ion channels. Proc. Natl. Acad. Sci. U.S.A. $108,8821-8825$.

Jones, P. L., Pask, G. M., Romaine, I. M., Taylor, R. W., Reid, P. R., Waterson, A. G., Sulikowski, G. A., and Zwiebel, L. J. (2012). Allosteric antagonism of insect odorant receptor ion channels. PLOS ONE 7, e30304. doi: 10.1371/journal.pone.0030304

Law, J. H., and Regnier, F. E. (1971). Pheromones. Annu. Rev. Biochem. 40, 533-548.

Lu, T., Qiu, Y. T., Wang, G., Kwon, J. Y., Rutzler, M., Kwon, H. W., Pitts, R. J., Van Loon, J. J., Takken, W., Carlson, J. R., and Zwiebel, L. J. (2007). Odor coding in the maxillary palp of the malaria vector mosquito Anopheles gambiae. Curr. Biol. 17, 1533-1544.

Lundin, C., Kall, L., Kreher, S. A., Kapp, K., Sonnhammer, E. L., Carlson, J. R., Heijne, G., and Nilsson, I. (2007). Membrane topology of the Drosophila OR83b odorant receptor. FEBS Lett. 581, 5601-5604.

Malnic, B., Hirono, J., Sato, T., and Buck, L. B. (1999). Combinatorial receptor codes for odors. Cell 96, 713-723.

Nakagawa, T., Sakurai, T., Nishioka, T., and Touhara, K. (2005). Insect sex-pheromone signals mediated by specific combinations of olfactory receptors. Science 307, 1638-1642.

Neubig, R. R., Spedding, M., Kenakin, T., and Christopoulos, A. (2003). International union of pharmacology committee on receptor nomenclature and drug classification. XXXVIII. Update on terms and symbols in quantitative pharmacology. Pharmacol. Rev. 55, 597-606.

Neuhaus, E. M., Gisselmann, G., Zhang, W., Dooley, R., Stortkuhl, K., and Hatt, H. (2005). Odorant receptor heterodimerization in the olfactory system of Drosophila melanogaster. Nat. Neurosci. 8, 15-17.

Pellegrino, M., Steinbach, N., Stensmyr, M. C., Hansson, B. S., and Vosshall, L. B. (2011). A natural polymorphism alters odour and DEET sensitivity in an insect odorant receptor. Nature 478, 511-514.

Pelletier, J., Hughes, D. T., Luetje, C. W., and Leal, W. S. (2010). An odorant receptor from the southern house mosquito Culex pipiens quinquefasciatus sensitive to oviposition attractants. PLoS ONE 5, e10090. doi: 10.1371/journal.pone.0010090

Sato, K., Pellegrino, M., Nakagawa, T., Nakagawa, T., Vosshall, L. B., and Touhara, K. (2008). Insect olfactory receptors are heteromeric ligandgated ion channels. Nature 452, 1002-1006.

Smart, R., Kiely, A., Beale, M., Vargas, E. Carraher, C., Kralicek, A. V., Christie, D. L., Chen, C., Newcomb, R. D., and Warr, C. G. (2008). Drosophila odorant receptors are novel seven transmembrane domain proteins that can signal independently of heterotrimeric $\mathrm{G}$ proteins. Insect Biochem. Mol. Biol. 38, 770-780.

Syed, Z., and Leal, W. S. (2007). Maxillary palps are broad spectrum odorant detectors in Culex quinquefasciatus. Chem. Senses 32, 727-738.

Syed, Z., and Leal, W. S. (2008). Mosquitoes smell and avoid the insect repellent DEET. Proc. Natl. Acad. Sci. U.S.A. 105, 13598-13603.

Wang, G., Carey, A. F., Carlson, J. R. and Zwiebel, L. J. (2010a). Molecular basis of odor coding in the malaria vector mosquito Anopheles gambiae. Proc. Natl. Acad. Sci. U.S.A. 107, 4418-4423.

Wang, G., Vasquez, G. M., Schal, C., Zwiebel, L. J., and Gould, F. (2010b). Functional characterization of pheromone receptors in the tobacco budworm Heliothis virescens. Insect Mol. Biol. 20, 125-133.

Wanner, K. W., Nichols, A. S., Allen, J. E., Bunger, P. L., Garczynski, S. F., Linn, C. E., Robertson, $\mathrm{H}$ M., and Luetje, C. W. (2010). Sex pheromone receptor specificity in the European corn borer moth, Ostrinia nubilalis. PLoS ONE 5, e8685. doi: 10.1371/journal.pone.0008685

Wanner, K. W., Nichols, A. S., Walden, K. K., Brockmann, A., Luetje, C. W., and Robertson, H. M. (2007). A honey bee odorant receptor for the queen substance 9-oxo-2-decenoic acid. Proc. Natl. Acad. Sci. U.S.A. 104, 14383-14388.

Wicher, D., Schafer, R., Bauernfeind, R., Stensmyr, M. C., Heller, R., Heinemann, S. H., and Hansson, B. S. (2008). Drosophila odorant receptors are both ligand-gated and cyclic-nucleotide-activated cation channels. Nature 452, 1007-1011.

Xia, Y., Wang, G., Buscariollo, D., Pitts, J., R., Wenger, H., and Zwiebel, L. (2008). The molecular basis of olfactory-based behavior in Anopheles gambiae larvae. Proc. Natl. Acad. Sci. U.S.A. 105, 6433-6438.

Conflict of Interest Statement: The authors declare that the research was conducted in the absence of any commercial or financial relationships that could be construed as a potential conflict of interest.

Received: 14 May 2012; paper pending published: 14 June 2012; accepted: 26 June 2012; published online: 13 July 2012.

Citation: Bohbot JD and Dickens JC (2012) Selectivity of odorant receptors in insects. Front. Cell. Neurosci. 6:29. doi: 10.3389/fncel.2012.00029

Copyright (c) 2012 Bohbot and Dickens. This is an open-access article distributed under the terms of the Creative Commons Attribution Non Commercial License, which permits non-commercial use, distribution, and reproduction in other forums, provided the original authors and source are credited. 